\title{
Psychological Sequelae of War-Related Disabilities on Children
}

\author{
Vivian Khamis \\ American University of Beirut, Beirut, Lebanon
}

\begin{abstract}
There is growing evidence that war exposure exerts a pernicious influence on children's psychosocial adjustment; however research on siblings of individuals with war-related disabilities remains underdeveloped.

The study investigated predictors of post-traumatic symptomatology, and psychosocial disorders in siblings of children who sustained war-related injuries that caused permanent disability. Questionnaires were used with 406 siblings of both genders with a mean age of 12.50 years. Results indicated that injury severity, gender and attributional style were related to psychosocial disorders and symptoms of post-traumatic stress, except for gender and post-traumatic stress. Siblings of children with severe injury appeared to be at greater risk for intrusive thoughts and avoidance as well as psychosocial disorders with females exhibiting more emotional and behavioral problems than did males. Siblings with more maladaptive attributional styles endorsed more emotional-behavioral problems and PTSD symptoms. Strengthening coping abilities to enhance cognitive control may be used with siblings at risk, particularly females and siblings of children who sustained a severe injury. Treatments such as attribution therapy may incur positive results. Psychological Sequelae of War-Related Disabilities on Children
\end{abstract}

\section{Introduction}

Catastrophic injuries of children during war have long-term psychological consequences on their siblings. There is growing evidence that war exposure exerts a pernicious influence on children's psychosocial adjustment including symptoms of posttraumatic stress

disorder, anxiety, and depression [16]. Despite such advances, research on siblings of individuals with warrelated disabilities remains underdeveloped.

Researchers of traumatic stress have focused their attention upon a wide range of variables that have influenced the course of children adjustment to injuries during war such as the severity of injury.For example, studies have found that many of the Palestinian children who were injured during war were diagnosed as having PTSD with excess risk for chronic symptoms and comorbidity with other psychiatric disorders such as anxiety and depression [16], [17], [19]. While some studies reported strong relationships between severity of injury and PTSD, other studies did not confirm any relationship [16], [19]. In fact, siblings of children with severe injuries who acquired a permanent disability may be at risk for increased distress and symptomatology due to the sudden changes in living arrangements, schedules, parenting practices, and the amount of time spent with their parents

Several investigators have consistently found substantial and significant positive correlations between self-reported depression and the composite of internal, stable, and global attributions for negative events and have occasionally found significant negative correlations between self-reported depression and the composite of internal, stable, and global attributions for positive events [11], [30]. Therefore, one might expect that attributional style may be the factor that mediates the relationship between war-related disabilities and its psychological sequelae.

According to learned helplessness theory [1], [27], [29] individuals who attribute negative outcomes to internal, stable and global causes are more likely to be depressed than those who attribute negative outcomes to 
external, unstable, and specific causes. Conversely, attribution of positive outcomes to external, unstable, and specific causes is positively related to depressive symptoms. The learned helplessness model predicts that the symptoms of helplessness, which overlap considerably with the symptoms of PTSD and internalizing and externalizing behaviors, will be due to the expectations that the individual has concerning the uncontrollability of the present and future circumstances. The model contends that the explanations that the individual gives himself for the causes of past events will influence these expectations. This explanatory style could be shaped by a traumatic event such as the war injury of a sibling.

The potential role of attributions in the development of victims' psychological and behavior problems has received the attention of clinical researchers [4], [22], [34] and falls within the purview of a key area of new research called "developmental victimology". For example, events that are less controllable and predictable are thought to be more likely to lead to posttraumatic stress disorder [10]. In fact, Foa and colleagues argued that the perceived uncontrollability and unpredictability of an event are so important that they should be incorporated into the definition of a traumatic event in the Diagnostic and Statistical Manual of Mental Disorders (DSM). Control appraisals also are a central component of more recent conceptual models of the development of PTSD symptoms [7], [26]. On the other hand, Gong-guy and Hammen found stronger relationships between attributions, including attributions of personal responsibility, stability and globality, when the event was the most upsetting event recalled by the individual.

Specific psychosocial theories indicated that gender is a characteristic that influences the stressors to which people are exposed [33], as well as the personal and social mediating resources that can be utilized to deal with hardship. Research results on trauma-related symptomatology and gender have been inconsistent. While some studies found that females were more likely to suffer from PTSD than males [28], other studies have found that the prevalence of PTSD was higher in males than females [21]. Relatedly, how gender roles affect the outcomes of war - related injury in siblings may also be prompted by the findings that girls tend to report more

Copyright @ 2017, Infonomics Society affection and intimacy in their sibling relationships than boys

Studying the psychological sequelae of war-related disabilities on siblings and the mediating variables such as gender, severity of the disability and attributional style has various consequences for developing culturally sensitive models of intervention.

The purpose of this research,therefore, was to assess the prevalence of PTSD and psychosocial disorders in siblings of children who incurred war-related injuries. It was predicted that injury severity, gender and attributional style would account for a significant amount of the variance in PTSD symptomatology and psychosocial disorders in siblings of children who incurred war-related injuries. Specifically, it was hypothesized that children with maladaptive attributional style who make more internal- stable-global attributions for negative events and more externalunstable-specific attributions for positive events report more PTSD symptoms andpsychosocial disorders than do children with the reverse attributional style. In addition, it was hypothesized that symptoms of PTSD and psychosocial disorders would be associated with injury severity and gender regardless of the child's attributional style.

\section{Method}

\subsection{Sample Selection and Characteristics}

The primary sample included 420 siblings of children who incurred war-related injuries during the year of 2008. Of these, 406 were willing to participate in the study, for an overall response rate of $96.6 \%$. About 202 were males and 204 were females. They ranged in age from 11 to 14 years $(M=12.50$ years, $S D=1.13)$. Fifty -one percent $(n=207)$ of the participants were in the mildly injured group where as $49 \%(n=199)$ were in the severely injured group.

\subsection{Procedure}

To be eligible to participate in this study, siblings had to be free of war injuries and serious physical problems. They also had to have a brother or a sister who sustained a war injury. One sibling was selected 1118 
from the three- and four-child families based on age (11 years and above), gender and severity of injury. Siblings were assigned to the severely injured group when their brother or sister had an injury that resulted in permanent disability such as paraplegia, and quadriplegia whereas those who were assigned to the mildly injured group had an injured brother or sister who recovered and did not incur any disability. Questionnaires were filled by the participants independently.

\subsection{Instrumentation. Siblings Data Sheet}

The Siblings data sheet provided information on gender, age and severity of injury.

\subsection{Strengths and Difficulties Questionnaire (SDQ)}

The $S D Q$ [13] was used to detect childhoodpsychosocial disorders. The SDQ is a brief 25 item behavioral screening instrument designed for use with children and teenagers between 4 and 16 years old. The 25 items are divided into five subscales each of five items, generating scores for conduct problems, hyperactivity/inattention, emotional symptoms, peer problems and pro-social behaviors. Internal consistency for each of the five subscales has been shown to be good with a mean Chronbach's alpha of 0.73. A total difficulties score ranging from 0 to 40 , representing increasing difficulties, is derived by summing scores on the first four of these sub-scales. The remaining scale, pro-social behavior, is a positive measure ranging from 0 to 10 representing increasing caring, helpful behavior. The self-report version of the SDQ for children aged 11 to 16 years was used in this study. The SDQ has been validated and used in previous studies among Palestinian children. The SDQ has been shown to discriminate between child mental health clinic attendees and community controlsand correlates highly with the longer Child Behavior Checklist (CBCL) [13].

\subsection{Impact of Event Scale (IES)}

The Impact of Event Scale (IES) was used to measure the psychological impact of events [14].The Copyright $\odot 2017$, Infonomics Society scale measures two dimensions of PTSD: trauma-related intrusion and avoidance. The frequencies of these symptoms were coded "not at all" 0 , "rarely" 1 , "sometimes " 3 , and "often" 5. It was developed using a non-combat sample, and has been shown to be psychometrically sound. The IES has been widely used with children. In a study that assessed the psychometric properties of the IES on the basis of a comprehensive list of studies, the results indicated that the IES' two factor structure is stable over different types of events, that it can discriminate between stress reactions at different times after the event, and that it has convergent validity with observer - diagnosed post-traumatic stress disorder. Previous research found good split-half reliability and one-week test-retest reliability for the total score [15]. In this sample Cronbach's alpha is .89 .

\subsection{The Children's Attributional Style Questionnaire -Revised (CASQ-R)}

The Children's Attributional Style Questionnaire Revised (CASQ-R) was used to assess causal attributions. It includes 24 forced-choice items, half addressing positive outcomes and half addressing negative outcomes [33]. For the 12 positive events, 2 items tap the internal-external dimension, 7 items assess the stable-unstable dimension, and 3 items address the global-specific dimension. For the 12 negative events, 3 items tap the internal-external dimension, 6 items assess the stable-unstable dimension, and 3 items address the global-specific dimension. Positive, negative, and overall (positive minus negative composite) scores are divided. The lower the positive composite score, the higher the negative composite score and the lower the overall composite score the more depressive is the attributional style. The mean for the overall composite in the CASQ-R was $4.87(S D=3.39)$ at Time1 and 4.96 $(S D=3.49)$ at Time2.

\subsection{Statistical analyses}

Pearson correlation coefficients were employed to examine the differences in perceived PTSD symptomatology and psychosocial disorders as a function of trauma severity, gender and attributional analysis. Then, separate stepwise regression analysis 
was used to examine the association between predictors and outcome measures.

\section{Results}

\subsection{General relations between psychosocial disorders, PTSD symptomatology and predictors}

Associations among the predictor and outcome variables were examined and are presented in Table 1 . Each of the predictors was related to siblings' psychosocial disorders (SDQ) and PTSD (IES). Among the variables, trauma severity was associated with negative attributions indicating that siblings of children with severe injuries had higher negative composite scores than their counterparts in the mild injuries group. Also, positive and negative attributions were negatively correlated in the expected direction. Gender wan not associated with positive and negative attributions nor with injury severity. Moderate positive correlations were also found between SDQ and IES.

Table 1. Intercorrelations of Predictor Variables and Outcome Measures

\begin{tabular}{|c|c|c|c|c|c|c|}
\hline Variables & 1 & 2 & 3 & 4 & 5 & 6 \\
\hline 1) Injury Severity & - & & & & & \\
\hline 2)Childs gender & -.09 & - & & & & \\
\hline $\begin{array}{l}\text { 3)Positive } \\
\text { Attributions }\end{array}$ & -.06 & -.02 & - & & & \\
\hline $\begin{array}{l}\text { 4)Negative } \\
\text { attributions }\end{array}$ & $.11^{*}$ & -08 & $\begin{array}{c}- \\
31^{* *} \\
*\end{array}$ & - & & \\
\hline $\begin{array}{l}\text { 5) Psychosocial } \\
\text { disorders (SDQ) }\end{array}$ & $.16^{* *}$ & $\begin{array}{c}- \\
16^{* * *}\end{array}$ & $\begin{array}{c}- \\
26^{* * *} \\
*\end{array}$ & $.27 * *$ & - & \\
\hline $\begin{array}{l}\text { 6) Posttraumatic } \\
\text { symptoms }\end{array}$ & $\begin{array}{c}21 * * \\
*\end{array}$ & -.08 & $1.3^{-}$ & $\begin{array}{c}- \\
26^{* *} \\
*\end{array}$ & $\begin{array}{c}32 * * * \\
*\end{array}$ & - \\
\hline
\end{tabular}

*Indicates $p<0.05$;**Indicates $p<0.001 ; * * *$ Indicates $p<0.0001$

Note: Gender is coded: Male $=1 ;$ Female $=0$. Injury severity is coded: Severe $=1$; Mild $=0$.

\subsection{Prediction of psychosocial disorders and PTSD symptomatology}

Separate stepwise regression analyses were employed to assess the contribution of injury severity, gender and attributional variables (negative and positive) topsychosocial disorders (SDQ) and PTSD (IES). The standardized beta weights and amounts of explained variance from the two analyses are presented Table 2.

Table 2. Prediction of children's psychosocial disorders (SDQ) and PTSD from injury severity, gender and attribution variables

\begin{tabular}{|c|c|c|c|c|c|c|c|c|}
\hline & & & $\begin{array}{l}\text { SD } \\
Q\end{array}$ & & & & IES & \\
\hline & beta & $R^{2}$ & $t$ & $p$ & beta & $\mathrm{R}^{2}$ & $t$ & $p$ \\
\hline $\begin{array}{l}\text { Injury } \\
\text { Severity }\end{array}$ & .116 & & $\begin{array}{l}2.4 \\
4\end{array}$ & .01 & .180 & & 3.73 & $\begin{array}{l}.000 \\
1\end{array}$ \\
\hline Gender & -.141 & & $\begin{array}{l}- \\
2.9 \\
7\end{array}$ & .003 & -3.1 & & -.05 & .28 \\
\hline $\begin{array}{l}\text { Positive } \\
\text { Attribution }\end{array}$ & .203 & & $\begin{array}{l}- \\
4.1 \\
0\end{array}$ & $\begin{array}{l}.000 \\
1\end{array}$ & -.05 & & $\overline{-}$ & .30 \\
\hline $\begin{array}{l}\text { Negative } \\
\text { Attribution }\end{array}$ & .189 & & $\begin{array}{l}3.7 \\
9\end{array}$ & $\begin{array}{l}.000 \\
1\end{array}$ & .22 & & 4.34 & $\begin{array}{l}.000 \\
1\end{array}$ \\
\hline Model & & .149 & & & & $\begin{array}{l}1 \\
06 \\
\end{array}$ & & $\begin{array}{l}.000 \\
1\end{array}$ \\
\hline
\end{tabular}

The results indicated that $14.9 \%$ of the variance in SDQ and $10.6 \%$ of the variance in IES could be predicted by the variables assessed. The models were statistically significant, $F$ 's $(4,391)=16.87$ and $11.60, p$ 's $<0.0001$, for SDQ and IES, respectively. All the predictors in the SDQ model were significant predictors. Siblings of children with severe injuries who acquired a permanent disability reported higher levels of psychosocial disorders than did siblings of children with mild injuries. Females reported higher levels of SDQ than did males. Also, the results indicated that positive and negative attributions were significant predictors of SDQ in siblings of children who sustained war -related injuries. Siblings, who reported lower positive composite score and higher negative composite score, had more psychosocial disorders. Among all the predictors in the IES model injury severity and negative attributions were the only significant predictors. Siblings of children who acquired a permanent disability reported higher levels of intrusive and avoidance thoughts than did siblings of $_{1120}$ 
children with mild injuries. Also, siblings with higher negative composite scores reported more PTSD.

\section{Discussion}

The results of the present study confirm previous research regarding the prevalence of PTSD and psychosocial disorders in children living in war zone areas [32], [2]. Approximately $21.6 \%$ of the siblings reported as having total difficulties score in the 'abnormal'range whereas the mean of the PTSD symptoms falls in the moderate range $(M=26.52, S D=$ 15.41). This high prevalence is comparable to the rate of PTSD found in children and adolescents exposed to the stress of extreme political violence [8], [16], [31].

The results indicated that injury severity, and negative attribution stood out as significant predictors of PTSD and psychosocial disorders.Previous studies on the injured of the intifada indicated that the severity and visibility of an injury intensify the process of assimilating the trauma by increasing negative selfconcept, frustration, concern about stigma and passing, and feelings of being disapproved of by others [31], [3]. Also, siblings of children with severe war - related injuries may be stressed by the additional burden of shared care by themselves [3], the experience of severe disruption following the injury [16] disrupted schedules, separation from parents, altered living arrangements, and changes in parenting behavior all compound the stress of siblings to heighten distress [5].

Consistent with previous findings, the results revealed that siblings with more maladaptive attributional styles reported more psychosocial problems and PTSD [33]. The finding that siblings with higher levels of negative attributional style reported more intrusive thoughts and avoidance (IES) is also consistent with Foa et al.'s [10] prediction that symptoms of PTSD would be enhanced by the perception of unexercised control and that children causal attribution is an important aspect of disaster response [15]. The research results also suggest that siblings who have positive attributions have lower levels of psychosocial problems. By contrast, positive attributional style mediated the effects of war injury on psychosocial adjustment only, suggesting that other explanatory mechanisms may be present for PTSD.

Copyright @ 2017, Infonomics Society
In this study, gender differences were found in regard to psychosocial disorders but not posttraumatic symptoms. The differential response between males and females are consistent with studies that associate gender and psychosocial disorders, with females experiencing more emotional symptoms than males [24].

\section{Conclusion}

Studies of siblings' responses to child's war injuries provide a window to understand traumatic stress after events that are indirectly experienced in contrast with directly experienced events [16]. Greater understanding of the impact of children's war-related injuries on siblings is required to better inform effective prevention approaches. As with any study, these results must be considered in the context of its limitations. The crosssectional design leaves the findings open to questions concerning the potential effects of retrospective selfreport bias. Any generalization of the results of the study may be limited to those who were listed by the Palestinian Society for the Care of Families of Injured (PSCFI) and could not include cases of injuries not reported for reasons of safety. It would be important to recognize the need to explore additional areas that are not tapped by this study such as the daily stressors encountered by siblings [23].

The results of the study also bear practical clinical implications. First, the predictor variables identified in the study can be used to identify siblings at risk of psychosocial disorders and PTSD symptoms in particular females and siblings of the severely injured who sustained a disability. Second, the associations between maladaptive attributional styles and psychosocial disorders and PTSD symptoms make it likely that attribution therapy such as modifying siblings' attributions of war-injuries may incur positive results.

Given the apparent significant relationship between psychological sequelae of intifada-related injuries and certain predictors (i.e., attributional analysis), treatments such as trauma-focused cognitive behavior therapy may incur positive results. Studies have proved that cognitive-behavioral therapy (CBT) effectively reduces PTSD symptoms and accompanying behavioral and emotional problems. Research on individuals with spinal 
cord injury indicated that cognitive-behavioral therapy was very beneficial for those who feel that they have little control over their lives [6].

\section{References}

[1] Abramson, L. Y., Seligman, M. E., \& Teasdale, J. D. (1978). Learned helplessness in humans: Critique and reformulation. Journal of Abnormal and Social Psychology, 87, 49-74. doi:10.1037/0021- 843X.87.1.49.

[2]Bourdon, K. H., Goodman, R., Rae, D., Simpson, G., \&Koretz, D. S., (2005). The Strengths and Difficulties Questionnaire: U.S. normative data and psychometric properties. Journal of the American Academy of Child and Adolescent Psychiatry.44, 557-564.

[3]Burke, P. (2010). Brothers and Sisters of Disabled Children: The Experience of Disability by Association. British Journal of Social Work, 40, 1681-1699.

[4]Celano, M. P. (1992). A developmental model of victims' internal attributions of responsibility for sexual abuse. Journal of Interpersonal Violence, 7, 57-69.

[5] Cozza, S., Guimond, J., McKibben, J., Chun, R., ArataMaiers, T., Schneider, B.,Maiers, A., Fullerton, C., \&Ursano, R. (2010). Combat-Injured Service Members and Their Families: The Relationship of Child Distress and SpousePerceived Family Distress and Disruption. Journal of Traumatic Stress, 23, 112-115.

[6] Craig, A., Hancock, K., Chang, E., \& Dickson, H. (1998). The effectiveness of group psychological intervention in enhancing perceptions of control following spinal cord injury. Australian and New Zealand Journal of Psychiatry, 32, 112118.

[7] Ehlers, A., \& Clark, D. M. (2000). A cognitive model of posttraumatic stress disorder. Behaviour Research and Therapy, 38, 319-345. doi: 10.1016/S0005-7967(99)00123-0.

[8] Elbedour, S., Onwuegbuzie, Ghannamc, J., Whitcome, J., \& Fadel Abu Hein, F. (2007). Post-traumatic stress disorder, depression, and anxiety among Gaza Strip adolescents in the wake of the second uprising (Intifada). Child Abuse \& Neglect, 31, 719-729.

[9] Foa, E. B., Steketee, G., and Rothbaum, B. O. (1989).Behavioral/cognitive conceptualization of PTSD.Behavior Therapy. 20, 155-176.
[10] Foa, E. B., Zinbarg, R., \& Rothbaum, B. O. (1992). Uncontrollability and unpredictability in posttraumatic stress disorder: An animal model. Psychological Bulletin, 112, 218 238. doi:10.1037/0033-2909.112.2.218

[11] Gladstone, T. R. G., \&Kaslow, N. J. (1995). Depression and attributions in children and adolescents: A meta-analytic review. Journal of AbnormalChild Psychology, 23, 597-606.

[12] Gong-guy, E., and Hammen, C. (1980). Causal perceptions of stressful events in depressed and nondepressed outpatients. J. Abnorm. Psychol. 89: 662-669.

[13] Goodman, R. (2001). Psychometric properties of the Strengths and Difficulties Questionnaire.Journal of the American Academy of Child and Adolescent Psychiatry, 40, $1337-1345$

[14] Horowitz, M. J., Wilner, N., \& Alvarez, W. (1979). Impact of event scale: a measure of subjective stress. Psychosomatic Medicine, 41, 209-218.

[15] Joseph, S., Yule, W., \&Williams ,R. (1993). PostTraumatic Stress: Attributional Aspects.Journal of Traumatic Stress, 6,501-513.

[16] Khamis, V. (1993a).Posttraumatic stress disorder among the injured of the intifada.Journal of Traumatic Stress, 6, 555559.

[17] Khamis, V. (1993b). Victims of the intifada: The psychosocial adjustment of the injured. Behavioral Medicine, 19, 93-101.

[18] Khamis, V. (2000).Political violence and the Palestinian family: Implications for mental health andwell-being. New York: Haworth Press.

[19] Khamis, V. (2005).Posttraumatic stress disorder among school-age Palestinian children. Child Abuse \& Neglect, 29, 81-95.

[20] Khamis, V. (2008).Post-traumatic stress and psychiatric disorders in Palestinianadolescents following intifada-related injuries.Social Science and Medicine, 67,1199-1207.

[21] Khamis, V. (2017) Psychological distress of parents in conflict areas: the mediating role of war atrocities, normative stressors and family resources. Journal of MentalHealth, 26:2, 104-110, DOI: 10.3109/09638237.2016.1139072 
[22] Mannarino, A. P., \& Cohen, J. A. (1996). Abuse-related attributions and perceptions, general attributions, and locus of control in sexually abused girls. Journal of Interpersonal Violence 11, 162-180.

[23] Miller, K. E., \& Rasmussen, A. (2010). Mental health and armed conflict: The importance of distinguishing between war exposure and other sources of adversity: A response to Neuner. Social Science \& Medicine, 71, 1385-1389.

[24] Muris, P., Meesters, C., \& van den Berg, F. (2003). The Strengths and Difficulties Questionnaire (SDQ): Further evidence for its reliability and validity in a community sample of Dutch children and adolescents. European Child and Adolescent Psychiatry, 12, 1-8.

[25] Neuner, F. (2010). Assisting war-torn populations-should we prioritize reducing daily stressors to improve mental health? Comment on Miller and Rosmussen (2010). Social Science \& Medicine, 71, 1381- 1384.

[26] Olff, M., Langeland, W., Draijer, N., \& Gersons, B. P. R. (2007). Gender differences in posttraumatic stress disorder. Psychological Bulletin, 133, 183-204. doi:10.1037/0033 2909.133.2.183.

[27] Peterson, C., \& Seligman, M. E. P. (1984). Causal explanations as a risk factor for depression: Theory and evidence. Psychological Review, 91, 347-374. doi:10.1037/0033-295X.91.3.347.

[28] Punama“ ki, R. L., Komproe, I., El Masri, M., Qouta, S., \& De Jong, J. T. V. M. (2005). The role of peritraumatic dissociation and gender in the association between trauma and mental health in a Palestinian community sample.American Journal of Psychiatry, 162, 545-551.

[29] Seligman, M. E. P. (1975). Helplessness: On depression, development, and death. San Francisco: Freeman.

[30] Shaver, K. (1970). Defensive attribution: Effects of severity and relevance on the responsibility assigned for an accident. Journal of Personality and Social Psychology, 14,101-113.

[31] Thabet, A., Abed, Y., \& Vostanis, P. (2002). Emotional problems in Palestinian children living in a war zone: a cross sectional study. Lancet, 359, 1801-1804.

[32] Thabet, A. A., Stretch, D., \&Vostanis, P. (2000). Child mental health problems in Arab children: Application of the
Strengths and Difficulties Questionnaire. International Journal of SocialPsychiatry, 46, 266-280.

[33] Thompson, M., Kaslow, N., \& Weiss, B. (1998). Children's Attributional Style Questionnaire-Revised: psychometric examination. Psychological Assessment, 10, 166-169.

[34] Wolfe, V. V, Gentile, C., \& Wolfe, D. A. (1989). The impact of sexual abuse on children: A PTSD formulation. Behavior Therapy, 20, 215-228. 